\title{
Muscular involvement in the Holt-Oram syndrome
}

Stephanie Spranger, Herbert Ulmer, Jochen Tröger, Olav Jansen, Jürgen Graf, Hans-Michael Meinck, Matthias Spranger

Institute of Human Genetics, University of Heidelberg, Im

Neuenheimer Feld 328, D-69120 Heidelberg, Germany

S Spranger

\section{Department of}

Paediatric Cardiology,

Heidelberg, Germany

H Ulmer

Department of

Paediatric Radiology,

University of

Heidelberg, Germany

J Tröger

Department of

Neuroradiology,

University of

O Jansen

Department of

Orthopaedics,

University of

Heidelberg, Germany

J Graf

Department of

Neurology, University

of Heidelberg,

Germany

H-M Meinck

$M$ Spranger

Correspondence to:

Dr Spranger.

Received 17 April 1997 publication 4 July 1997
University of

Heidelberg, Germany

Revised version accepted for

Abstract
Holt-Oram syndrome is an autosomal dominant disorder characterised by radial ray and congenital heart defects. Recently, a gene for this disorder has been identified on chromosome 12q24.1, encoding a $T$ box transcription factor. However, the functional role of the gene product is not completely understood. We present results of neurological, radiological, and muscle magnetic resonance imaging (MRI) investigations in 13 patients from eight unrelated families. Besides heart defects, clinical signs ranged from thenar abnormalities to bilateral phocomelia. The former were present in all patients. MRI showed hypoplasia of discrete muscles which clinically showed as nonprogressive weakness. The structural pattern of residual muscles was normal on MRI, which together with normal muscular power, electromyography, and muscle enzyme investigations excluded a progressive neuromuscular disorder. The number and location of hypoplastic muscles correlated with the severity of skeletal involvement. Thus, patients with hypoplasia of large and proximal muscles had phocomelia, and those with mere intrinsic hand muscle hypoplasia had only a triphalangeal thumb or no skeletal malformation. On the basis of these observations, we conclude that disturbed fetal limb muscle development is involved in the bony malformations of the upper limbs. $(\mathcal{F}$ Med Genet 1997;34:978-981)

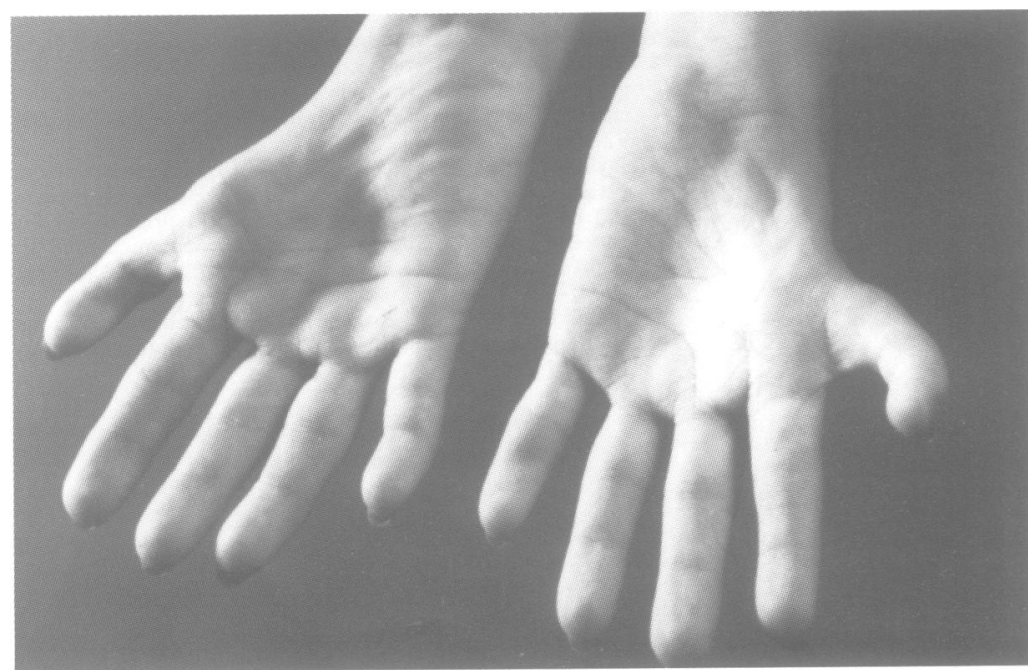

Figure 1 Thenar hypoplasia in a patient with HOS.
Keywords: Holt-Oram syndrome; magnetic resonance imaging; muscle hypoplasia; thenar hypoplasia

The Holt-Oram syndrome (HOS) is a rare autosomal dominant disorder with an estimated prevalence of 1:100 000. ${ }^{1}$ Recently, a gene for HOS has been identified (HOS1) on chromosome 12q24.1, which encodes the human transcription factor TBX $5 .^{23}$ The mutations described in this gene introduce a premature stop codon and result in truncated protein versions. The role of TBX 5 in human embryonic development and in the pathogenesis of HOS deserves further clarification.

The characteristic clinical manifestations of HOS are congenital heart defects, comprising VSD, ASD, and AV block, and variable skeletal malformations of the arms. ${ }^{145}$ The spectrum of skeletal abnormalities ranges from mildly affected patients with triphalangeal thumb or sloping shoulders to bilateral phocomelia. The limb defects tend to be bilateral and asymmetrical, affecting the left side more severely than the right. ${ }^{16}$ Muscle involvement in HOS has occasionally been mentioned and considered as a secondary finding. ${ }^{17}$

Here we studied the distribution of affected muscles in a systemic approach using electromyography (EMG) and magnetic resonance imaging (MRI), which allows in vivo visualisation of the texture of discrete muscles. Based on our observations we conclude that muscular hypoplasia is a major manifestation of HOS.

\section{Patients and methods}

We investigated 13 patients with HOS, 10 females and three males, from eight families. Five cases were sporadic and eight cases were familial in three unrelated families. All patients met the criteria proposed by Newbury-Ecob et $a l,{ }^{1}$ including radial ray defects and septal defect or AV block in at least one family member. Before this study, all patients had had extensive radiological documentation of the chest and upper limbs, and cardiac examination comprising electrocardiogram, echocardiogram, and cardiac catheter investigation in some patients to establish the diagnosis and for preoperative diagnosis.

Lower limb involvement, deafness, and facial abnormalities were excluded by careful clinical examination. Normal white and red blood cell counts, normal thrombocytes, and lack of hearing impairment, anal atresia, or vertebral defects excluded TAR syndrome, Fanconi syndrome, Okihiro syndrome, and VATER association. $^{8-11}$ 
Table 1 Skeletal and muscle manifestations

\begin{tabular}{|c|c|c|c|c|c|c|c|c|c|c|c|c|c|c|}
\hline \multicolumn{2}{|l|}{ Family No } & \multicolumn{2}{|l|}{$I$} & \multicolumn{4}{|l|}{$I I$} & \multicolumn{2}{|l|}{$I I I$} & \multirow{4}{*}{$\begin{array}{l}I V \\
9 \\
\mathrm{~F} \\
25\end{array}$} & \multirow{4}{*}{$\begin{array}{l}V \\
10 \\
M \\
10\end{array}$} & \multirow{4}{*}{$\begin{array}{l}V I \\
11 \\
\mathrm{~F} \\
4\end{array}$} & \multirow{4}{*}{$\begin{array}{l}V I I \\
12 \\
M \\
7\end{array}$} & \multirow{4}{*}{$\begin{array}{l}\text { VIII } \\
13 \\
\mathrm{~F} \\
4\end{array}$} \\
\hline Patient No & & 1 & 2 & 3 & 4 & 5 & 6 & 7 & 8 & & & & & \\
\hline $\begin{array}{l}\text { Gender } \\
\text { Age }\end{array}$ & & $\mathrm{F}$ & $\mathbf{M}$ & $\mathrm{F}$ & $\mathrm{F}$ & $\mathbf{F}$ & $\mathbf{F}$ & $\mathbf{F}$ & $\mathrm{F}$ & & & & & \\
\hline $\begin{array}{l}\text { Age } \\
\text { Cardiac }\end{array}$ & & 35 & 14 & 32 & 3 & 33 & 1 & 31 & 1 & & & & & \\
\hline \multirow{2}{*}{$\begin{array}{l}\text { Cardiac } \\
\text { involvement }\end{array}$} & AV block & + & + & & & & & & & & & & & \\
\hline & ASD/VSD & & & + & + & + & + & + & + & + & + & + & + & + \\
\hline \multirow{10}{*}{$\begin{array}{l}\text { Skeletal } \\
\text { malformations }\end{array}$} & Hypoplastic scapula & + & + & - & - & - & - & - & - & - & - & + & - & - \\
\hline & Clavicular hooks & - & - & + & + & + & - & + & - & + & + & - & - & + \\
\hline & Hypoplastic humerus & + & + & - & - & - & - & - & - & + & + & - & - & - \\
\hline & Triangular humerus & + & - & - & - & - & - & - & - & + & + & + & - & - \\
\hline & Radial hypo-/aplasia & + & - & - & - & - & - & - & - & + & + & + & + & - \\
\hline & Radioulnar synostosis & - & + & - & - & - & - & - & - & + & - & - & - & - \\
\hline & Ulna & + & - & - & - & - & - & - & - & - & - & + & - & - \\
\hline & Aplasia of $1 \mathrm{st} / 2 \mathrm{nd}$ ray & + & - & - & - & - & - & - & - & + & + & + & + & - \\
\hline & $\begin{array}{l}\text { Triphalangeal thumb } \\
\text { Thumb hypoplasia/proximal }\end{array}$ & & + & - & - & + & - & + & + & & + & & & - \\
\hline & inserted thumb & & + & + & + & - & - & - & + & & - & & & + \\
\hline \multirow{7}{*}{$\begin{array}{l}\text { Muscular } \\
\text { weakness }\end{array}$} & Trapezium muscles & - & + & + & + & + & + & + & ? & - & + & - & - & + \\
\hline & Pectoral muscle & - & + & - & - & - & ? & - & $?$ & + & + & + & - & - \\
\hline & $\begin{array}{l}\text { Deltoid, biceps, triceps muscles } \\
\text { Wrist extensors, ulnar }\end{array}$ & + & + & - & - & - & ? & - & ? & + & + & + & + & - \\
\hline & abductors, supinators & + & + & - & - & + & $?$ & + & $?$ & + & + & + & + & - \\
\hline & Thenar muscles & + & + & + & + & + & + & + & + & + & + & + & + & + \\
\hline & Flexion contractures in elbow & + & - & - & - & - & - & - & - & + & + & + & - & - \\
\hline & $\begin{array}{l}\text { Radial/flexion contracture in } \\
\text { wrist }\end{array}$ & + & - & - & - & - & - & - & - & + & + & + & + & - \\
\hline
\end{tabular}

+ affected, - not affected, ? not known owing to young age.
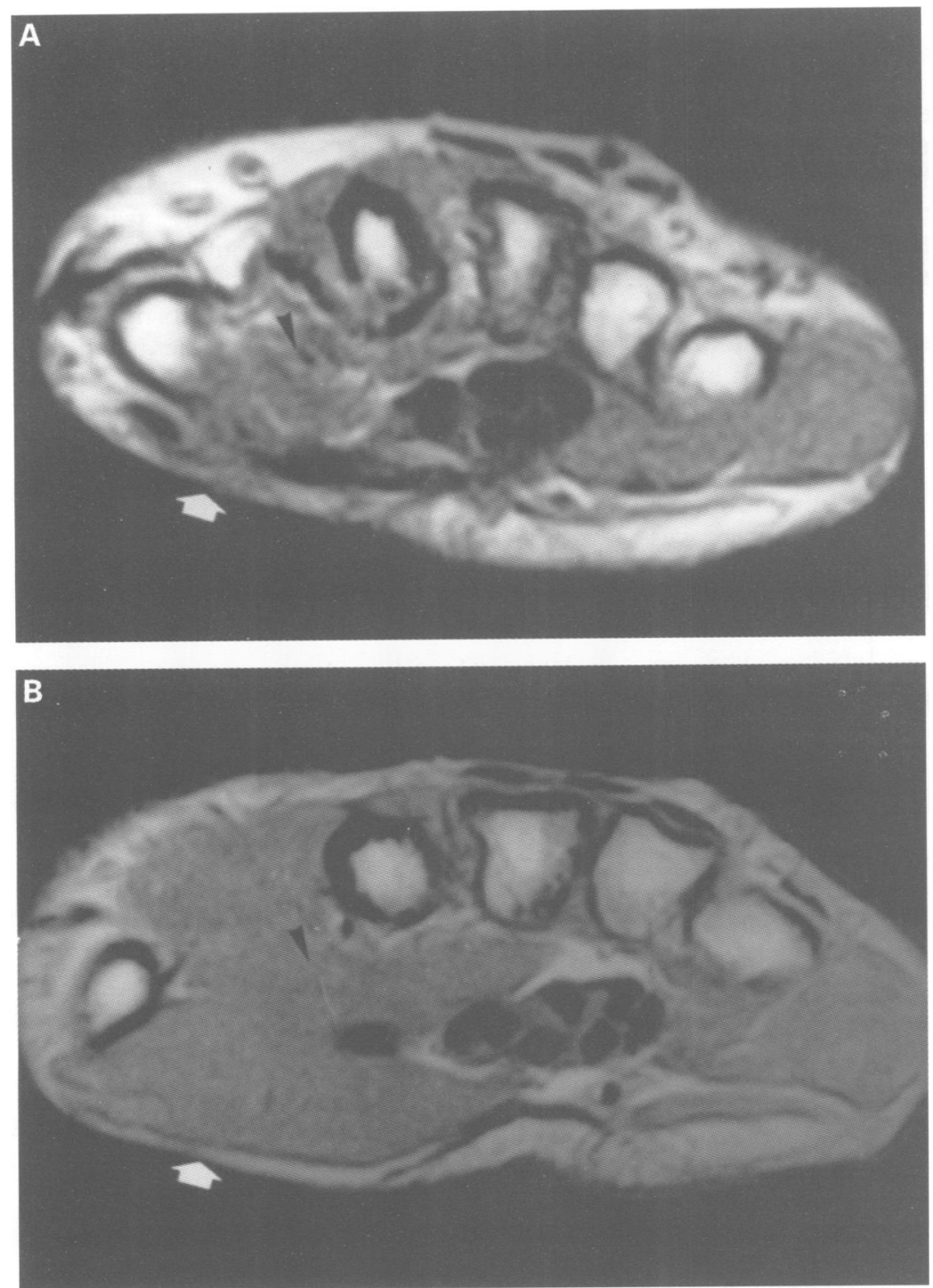

Figure 2 MRI (T1 weighted image, axial plane) of the hand muscles in a patient with HOS $(A)$ in comparison to a normal control $(B)$. Note hypoplasia of the opponens and abductor pollicis brevis muscles (arrows).
In this study, a complete neurological status was obtained for all patients. In all adult patients, muscular enzymes were investigated and an EMG was recorded from the affected muscles. Additionally, MRI of the affected limb was performed using a 1.5 tesla scanner with a surface coil. T1 weighted images (SE 640/20/1, repetition time/echo time/excitations) were obtained in the axial and coronal planes and T2 weighted images (FSE 2500/80) were obtained in the axial plane.

\section{Results}

Heart defects were observed in all patients and comprised 1st and 3rd grade AV block, atrial and ventricular septal defects, with multiple defects in two cases (table 1).

Radiological examination disclosed variable skeletal malformations of the upper limbs (table 1). Five patients were affected asymmetrically with more severe malformations on the left side. Eight patients had symmetrical involvement. One patient lacked any radiological limb abnormalities, but had bilateral clavicular hooks; three others had additional proximally inserted or hypoplastic thumbs. Four patients had triphalangeal thumbs, associated in one of them with severe reduction defects on the left side. Four patients had severe reduction defects, one of them unilateral, including hypoplastic, triangular humeri, extremely shortened radius, and thumb aplasia.

Physical examination disclosed abnormalities of the upper limb and discrete truncal muscles. In all patients thenar muscles were affected with complete paresis of thumb abduction and opposition (fig 1). In 12 patients, additional moderate muscular weakness was observed of the wrist extensor, supinator, biceps brachii, triceps brachii, deltoid, pectoral, or trapezium muscles (table 1). 

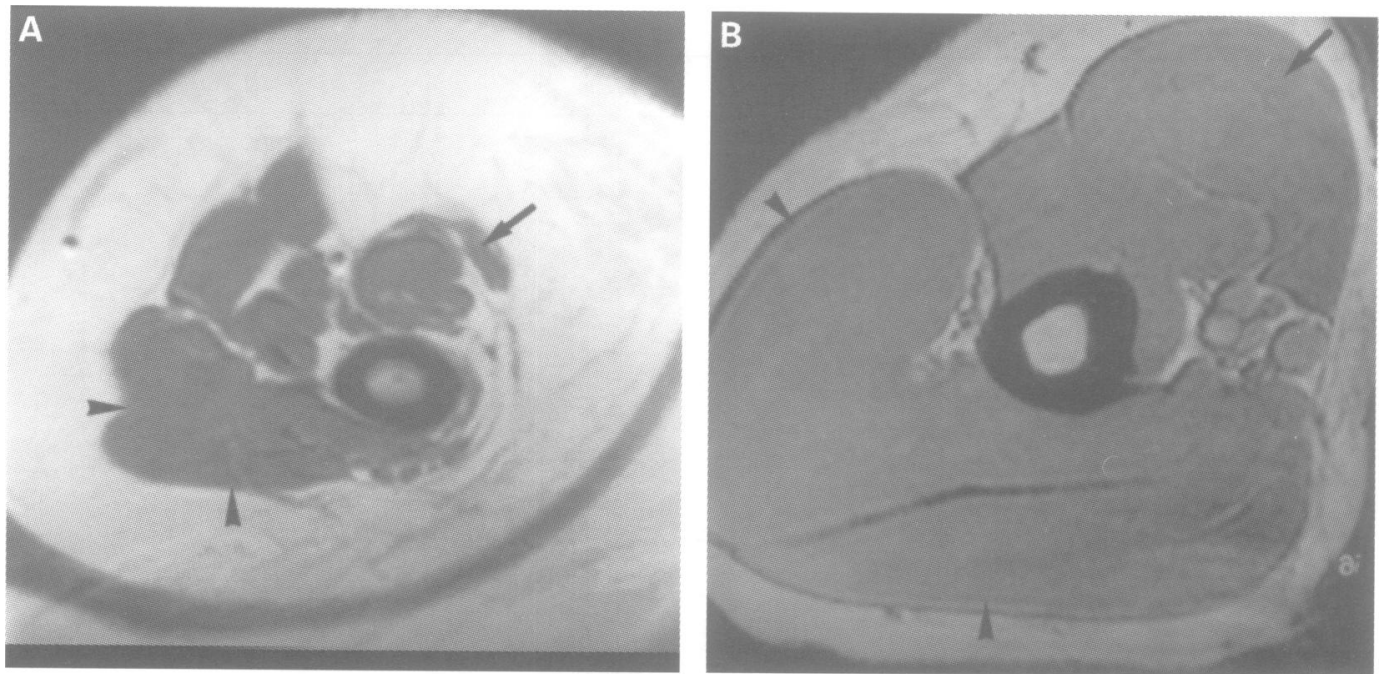

Figure 3 MRI (T1 weighted image, axial plane) of upper arm muscles from a severely affected patient with shortened, triangular humerus (A) in comparison to a normal control (B). Note hypoplasia of the biceps (arrows) and triceps (arrow heads) brachii muscles.

In the more severely affected patients, wrist contractures with radial and flexion deviation were noted. This corresponded to weakness of the extensor muscles which was more pronounced in the extensor carpi ulnaris than the extensor carpi radialis muscles. In all patients the flexor muscles of the wrist were of normal strength.

In order to analyse the nature of the muscle weakness, EMG was performed in four adult patients. Normal results were obtained in moderately paretic muscles. Additionally, normal creatine kinase levels in serum in these patients excluded a progressive neuromuscular disorder.

MRI investigations disclosed normal structural patterns of muscle tissue. Isolated hypoplasia of opponens and abductor pollicis brevis muscles was noticed in the hands (fig 2) and in other patients supinator and extensor muscles in the forearm and the triceps muscle in the upper arm were hypoplastic (fig 3). There was no fatty or fibrotic transformation of preexisting muscles documenting true hypoplasia of distinct muscles.

The localisation of muscle involvement correlated with the skeletal malformations. Isolated hypoplasia of the thenar muscles was found in the patient without bony defects and in those with minor malformations, such as thumb hypoplasia and proximally inserted thumb. In patients with more severe bone malformations, additional weakness and hypoplasia in MRI investigations of more proximal muscle groups was found (table 2). Patients with skeletal abnormalities confined to the hand had weakness of the distal forearm mus-

Table 2 Clinical investigations

\begin{tabular}{lll}
\hline Muscle weakness & Bone malformation & $\begin{array}{l}\text { No of } \\
\text { patients* }\end{array}$ \\
\hline Pectoralis, deltoid & Humoral hypoplasia, shortened radius, aplasia of & 5 \\
Supinator, brachioradialis & 1st and 2nd ray & 2 \\
Hand and finger extensors & Radial hypoplasia and aplasia of 1st ray & 3 \\
Abductor and opponens pollicis & Triphalangeal thumb & None or mildly hypoplastic thumb
\end{tabular}

*Two patients had asymmetrical involvement, leading to classification of left and right limb in different categories. cles. When the radius or ulna or both were also affected, muscle weakness extended to supination or flexion in the elbow. In the three patients with severe upper limb reduction defects, we found weakness and atrophy of the upper arm and shoulder muscle groups including the pectoralis and deltoid muscles.

In addition to the limb malformations, 10 of the 13 patients had abnormalities of the truncal bones and muscles. They presented with sloping shoulders, clavicular hooks or shortened clavicles, and weakness of the trapezium muscle with consequent scapular winging (fig 4). The involvement of truncal muscles did not correlate with the severity of limb malformation, since it was observed in patients with no

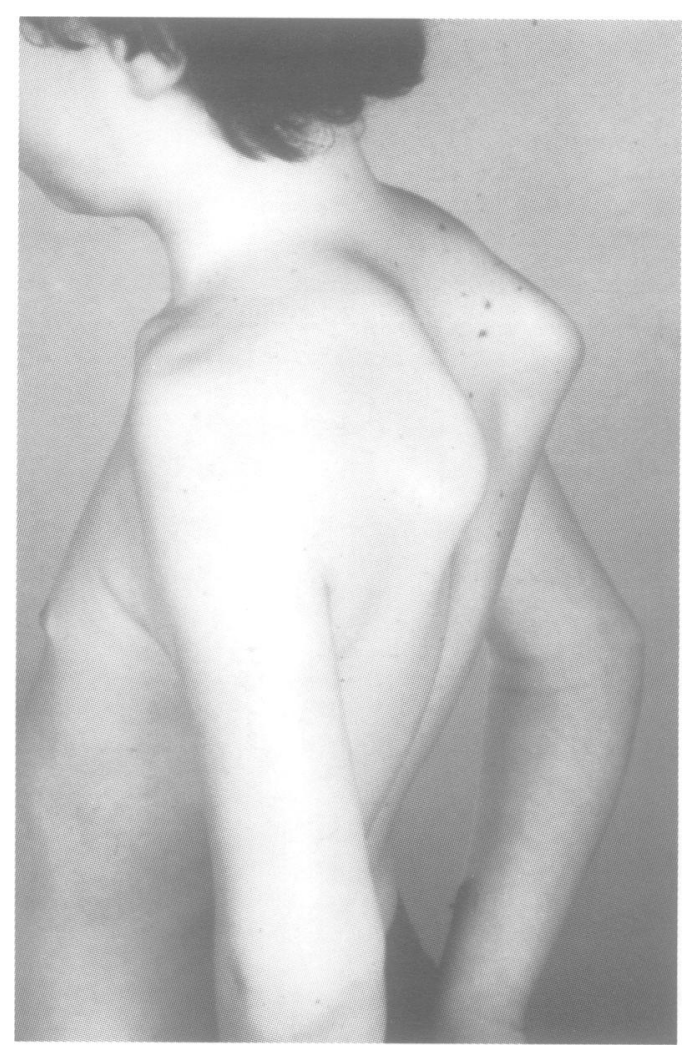

Figure 4 Scapular winging of the trapezium type in a patient with HOS. 
or minor bony limb defects. On the other hand, one patient with severe reduction defects of the upper limbs lacked involvement of truncal muscles and bones.

\section{Discussion}

In all patients with HOS investigated, we observed muscular abnormalities ranging from weakness to hypoplasia of discrete muscles. Electromyography and muscle enzyme investigations were normal and excluded a progressive neuromuscular disorder. In addition, the structural pattern of residual muscles appeared normal on MRI investigation.

Muscle involvement in HOS has been mentioned in single cases previously. ${ }^{72}$ In a large study of 55 cases with HOS, Newbury-Ecob et $a l^{1}$ described minor clinical signs such as sloping shoulders, limited supination, and in the majority of patients hypoplasia of the thenar eminence.

Minimal muscular abnormalities in our HOS patients comprised hypoplasia of the thenar muscles as confirmed by MRI and trapezium weakness with scapular winging. These findings should be considered separately, since the embryogenic development of the trapezium muscle differs from that of limb muscles. The myoblasts that form the skeletal muscles of the trunk are derived from the mesoderm in the myotome regions of the somites. In contrast, the limb muscles develop from mesenchyme in the limb buds that is derived from the somatic mesoderm. The trapezium muscle inserts in the lateral third of the clavicle and in the scapula. Thus, weakness of this muscle gives the clinical impression of sloping shoulders and scapular winging, as observed frequently in HOS patients.

In our mildly affected patients, MRI disclosed the opponens and abductor pollicis brevis muscles to be hypoplastic with all other thenar muscles intact. These patients had no bony abnormalities or hypoplastic thumbs. Thus, the muscular insertion site should be intact, which is supported by the normal function of thumb flexors and extensors. Additionally, passive joint mobility was not limited by these minor muscular malformations, which excluded muscular atrophy by inactivity. In more severely affected patients, proximal muscles were involved. Clinical and MRI investigations disclosed that as a rule paresis and hypoplasia of discrete muscles were located proximally to the radiologically apparent bone malformation (table 2).

The relationship of muscle abnormality and skeletal malformation is obscure. Both may be associated findings. Based on our clinical observations we also put forward the hypothesis that skeletal limb malformations might be secondary to a muscle disorder. Recently, one gene for HOS was identified on chromosome $12 \mathrm{q} 24.1 .^{23} \mathrm{It}$ is a member of the brachyury (T) gene family and encodes a transcription factor (TBX5). Mutations of the mouse homologue, tbx5, result in a failure to activate the transcription of mesoderm specific genes and their downstream targets. ${ }^{13}$ Tissue in situ hybridisation analysis of TBX 5 expression in human embryos from day 26 to 52 of gestation detected high levels of expression in the limbs and heart. ${ }^{3}$ Further evidence for the role of TBX5 during myogenesis has been obtained in zebrafish. ${ }^{14}$ Homozygote mutant zebrafish for $\mathrm{ntl}$, a homologue of the murine brachyury $\mathrm{T}$ gene, did not develop muscle pioneer cells, and their trunk myotomes did not achieve the characteristic chevron shape. These data derived from animal models in conjunction with our observation of hypoplasia of discrete muscle groups in HOS patients support the hypothesis that disturbed muscle development plays an important role in the pathogenesis of HOS. Further studies should focus on the time and spatial distribution of tbx 5 gene expression in the various tissues of the limb, including myogenic precursor cells, and the impact of its mutation on muscle and bone development.

1 Newbury-Ecob RA, Leanage R, Raeburn JA, Young ID. Holt-Oram syndrome: a clinical genetic study. $\mathcal{F}$ Med Genet 1996;33:300-7.

2 Basson CT, Bachinsky DR, Lin CR, et al. Mutations in human (TBX5) cause limb and cardiac malformation in Holt-Oram syndrome. Nat Genet 1997;15:30-5.

3 Li YQ, Newbury-Ecob R, Terrett JA, et al. Holt-Oram syndrome is caused by mutations in TBX 5 , a member of the Brachyury (T) gene family. Nat Genet 1997;15:21-9.

4 Gall JC, Stern AM, Cohen MM, Adams MS, Davidson RT. Gall JC, Stern AM, Cohen MM, Adams MS, Davidson RT.
folt-Orame. Clinical and genetic study of a large family. Am f Hum Genet 1966;18:187-200.

5 Smith AT, Sack GH, Taylor GJ. Holt-Oram syndrome. $\mathcal{f}$ Pediatr 1979;95:538-43.

6 Najjar H, Mardini M, Tabbaa R, Nyhan WL. Variability of the Holt-Oram syndrome in Saudi individuals. $A m \mathcal{F} M e d$ Genet 1988;29:851-5.

7 van Regemorter N, Haumont D, Kirkpatrick C, et al. HoltOram syndrome mistaken for thalidomide embryopathy Oram syndrome mistaken for thalidomide embryopathy -
embryological considerations. Eur f Pediatr 1982;138:77-

8 Hall JG. Thrombocytopenia and absent radius (TAR) syndrome. $\mathcal{F}$ Med Genet 1987;24:79-83.

9 Glanz A, Fraser FC. Spectrum of anomalies in Fanconi anaemia. F Med Genet 1982;19:412-16.

10 Hayes A, Costa T, Polomeno RC. The Okihiro syndrome of Duane anomaly, radial ray abnormalities, and deafness. $\mathrm{Am}$ $f$ Med Genet 1985;22:273-80.

11 Quan L, Smith DW. The VATER-association. 7 Pediatr 1973;82:104-7.

12 Braulke I, Herzog S, Thies U, Zoll B. Holt-Oram syndrome in four half-siblings with unaffected parents: brief clinical in four half-siblings with unaffected

13 Herrmann BG, Kispert A. The T genes in embryogenesis. Trends Genet 1994;10:280-6.

14 Halpern ME, Ho KR, Walker C, Kimmel CB. Induction of muscle pioneers and floor plate is distinguished by the zebrafish no tail mutation. Cell 1993;75:99-111. 